Labovitz School of Business \& Economics, University of Minnesota Duluth, 11 E. Superior Street, Suite 210, Duluth, MN 55802

On Southbound Ease and Northbound Fees: Literal Consequences of the Metaphoric Link Between Vertical Position and Cardinal Direction

Leif Nelson, University of California, San Diego

Joseph Simmons, Yale University

The metaphoric relationship between cardinal direction and vertical position influences consumers' price expectations and shopping decisions. Consumers implicitly associate "north" with "up" and "south" with "down." As a consequence, they judge difficult and "uphill" travel to be northward and northward travel to be difficult and "uphill." The perceived difficulty of northward travel increases consumers' price expectations for northward services and increases intentions to visit stores described as south of a reference point, especially when ease of travel is important.

[to cite]:

Leif Nelson and Joseph Simmons (2008),"On Southbound Ease and Northbound Fees: Literal Consequences of the Metaphoric Link Between Vertical Position and Cardinal Direction", in NA - Advances in Consumer Research Volume 35, eds. Angela Y. Lee and Dilip Soman, Duluth, MN : Association for Consumer Research, Pages: 233-236.

[url]:

http://www.acrwebsite.org/volumes/13351/volumes/v35/NA-35

\title{
[copyright notice]:
}

This work is copyrighted by The Association for Consumer Research. For permission to copy or use this work in whole or in part, please contact the Copyright Clearance Center at http://www.copyright.com/. 


\title{
Symposia Summary Advances in Judgmental and Inferential Heuristics
}

\author{
Xianchi Dai, INSEAD, France \\ Klaus Wertenbroch, INSEAD, France
}

\section{SESSION OVERVIEW}

To deal with the complexities of the world and with the cognitive constraints in facing these, people use heuristics to facilitate their everyday judgments and decisions. Since Tversky and Kahneman's (1974) seminal work, much progress has been made in research on heuristics and biases, as shown, for example, by two classical volumes of selected papers on this topic (Kahneman, Slovic, and Tversky, 1982; Gilovich, Griffin, and Kahneman, 2002). Within the consumer behavior field, a large body of research has examined the impact of various judgmental and inferential heuristics on consumer decisions. For example, availability or ease of retrieval has been shown to affect consumer judgments of product failure (Folkes, 1988), consumer recommendations and purchase intentions (Menon and Raghubir, 2003), and consumer evaluations of products (Tybout et al, 2005). Consumers also use their affect as information in making product and other consumer related evaluations (Adaval, 2001; Bickart and Schwarz, 2001; Pham, 1998). Furthermore, anchoring systematically affects consumer valuations (Ariely, Loewenstein, and Prelec, 2003; Simonson and Drolet, 2004), quantity purchase decisions (Wansink, Kent, and Hoch, 1998), and attitude formation (Cohen, Reed II, 2006; Lynch, 2006), to name just a few.

Despite the extensive research done in this field over the years, this session demonstrates that it remains a fertile area for continued research. The session presents three papers, each of which introduces a previously undiscovered heuristic that consumers use in their judgment and decision processes. The first paper examines how consumers' valuations of objects and experiences affect judgments of frequency, supply, and duration. The second paper studies consumers' use of a metaphoric link between vertical position and cardinal direction to infer traveling costs, which in turn systematically affects consumers' preferences and choices. The third paper shows how the consequences of events affect consumers' inferences of the causes of these events.

Dai, Wertenbroch, \& Brendl demonstrate in seven studies that consumers use the value of things to infer their relative frequency, quantity, and duration. Specifically, they judge what is more valuable as relatively scarcer. In the first four studies, they show that both inherent as well as experimentally induced value affect consumers' relative frequency judgments. Another three studies extends these findings to quantity as well as duration judgments. The results suggest that consumers underestimate the supply of what they value and thus make suboptimal purchase decisions.

Nelson \& Simmons show that the metaphoric link between cardinal direction and vertical position affects consumers' price expectations and shopping decisions. Specifically, consumers implicitly associate "north" with "up" and "south" with "down," which is corroborated by IAT results. Furthermore, this association systematically affects consumers' expectation of traveling costs, consumer's intention to redeem coupons at shops located in the south versus north of a reference point, as well as consumers' store choice decisions.

Finally, LeBoeuf \& Norton discuss consumers' inferences of the causes of events from their outcomes. They find that consumers use an outcome-cause matching strategy to make causal inferences. That is, a given event has a large cause if that event has a large outcome, but a small cause if the outcome is small. Across a series of studies, this outcome-cause matching effect is shown to hold along the magnitude and valence dimensions, with events in various domains.

Overall, the three papers were chosen for this session because (1) they unearth previously undiscovered strategies of consumer judgments and inferences that can cause surprising and serious biases and (2) they all share the same underlying process-attribute substitution-proposed by Kahneman and Frederick (2002). That is, whenever an attribute (the target attribute) of the judgmental object, which one wants to assess, is less readily assessed than a related property (the heuristic attribute), people may unwittingly substitute the simpler assessment of the heuristic attribute for the assessment of the target attribute. In the first paper, the target attribute is the relative frequency, quantity, or duration of a category, the heuristic attribute is the relative value of the category. In the second paper, the target attribute is the traveling cost to the shopping destination and the heuristic attribute is the cardinal direction. In the third paper, the event cause is the target attribute and the event outcome is the heuristic attribute. In most situations, the heuristic attribute and the target attribute are correlated. However, as demonstrated in the papers in this session, when the heuristic attribute is not diagnostic of the target attribute, the substitution process can bias judgments and thus lead to suboptimal consumer decisions. Together, the three papers form a cohesive set of explorations into some fundamental characteristics of consumer judgments and decision making. The session shows that research on heuristics and biases is alive and well by providing evidence of three completely new heuristics.

\section{EXTENDED ABSTRACTS}

\section{"The Value Heuristic" Xianchi Dai, INSEAD \\ Klaus Wertenbroch, INSEAD \\ C. Miguel Brendl, Northwestern University}

Research in psychology and economics has shown that people tend to judge what is scarcer as more valuable, which Cialdini (2001) called scarcity principle. We demonstrate a reversal of this scarcity-valuation link. That is, people heuristically infer what is more valuable as relatively scarcer. Across seven studies, we demonstrate the operation of this value heuristic in consumer judgments of relative frequency, quantity, and duration.

In study 1 , respondents underestimated the proportion of portraits of the opposite gender after they had seen and evaluated a series of male and female portraits appearing in a random order on a computer screen. Assuming that people prefer to look at portraits of the opposite gender, our respondents underestimated the relative frequency of the more valuable portraits. In study 2, we manipulated stimulus value directly, using two subsets of portraits, each with equal proportions of female and male faces. One subset included only attractive faces of both genders, the other only unattractive faces. Consistent with the value heuristic, both male and female respondents underestimated the frequency of portraits of the more desirable category (i.e., of attractive faces of the opposite gender) relative to the frequency of the less desirable category (i.e., of attractive faces of the opposite gender), whereas there was no such difference for unattractive faces. 


\section{4 / Advances in Judgmental and Inferential Heuristics}

To test whether these findings arose from an inferential retrieval heuristic rather than from a perceptual encoding effect, studies 3 and 4 induced a value difference only at the point of retrieval. In study 3 , we first asked participants to evaluate a series of 50 bird and 50 flower pictures, one at a time, appearing in a random order. Subsequently, we told them that they would receive $\$ 2$ for each occurrence of the target category (either birds or flowers); respondents flipped a coin to decide for which category they would get paid. After that, they estimated the number of pictures in each category. Those who were paid for flower pictures estimated that they had seen fewer flower pictures than bird pictures, whereas those who were paid for bird pictures estimated that they had seen fewer bird pictures than flower pictures. Study 4 tested the value heuristic for stimuli presented simultaneously rather than sequentially. Participants were first asked to memorize nonsensical blue and red letter combinations, presented to them on a computer screen. After that, participants again flipped a coin to determine whether they would get paid $\phi 2$ for each red or each blue letter combination they had been presented. Finally, we asked participants to estimate the frequency of the two categories. Again, participants estimated the more valuable category as relatively scarcer.

We also examined the value heuristic in quantity and duration judgments. In study 5, we asked respondents to estimate how many units of an attractive item (a \$50 offer of an almost new Sony TV set) were available on ebay.com at a given moment. We manipulated the salience of the value of this offer by varying whether or not respondents rated its attractiveness before estimating the supply. Respondents who provided attractiveness ratings estimated a lower supply than those who had not rated the attractiveness of the offer; making stimulus value salient lowers quantity estimates. In study 6 , participants first listened to a 90 second music clip. To manipulate respondents' valuations of the clip, we then asked them either for their willingness to accept (WTA; to induce a negative perception) or for their willingness to pay (WTP; to induce a positive perception; see Ariely, Loewenstein, and Prelec, 2006) to listen to the clip. Next, respondents estimated the duration of the music. As predicted by the value heuristic, duration estimates in the WTP condition were shorter than those in the WTA condition. Finally, study 7 manipulated value by asking participants to rate their liking of a music clip either before or after the duration estimation task. Similar to study 4 , we predicted that liking ratings would make value salient and thus affect subsequent duration judgments. The results confirmed our hypothesis. For attractive music clips, rating liking before the duration estimation task decreased duration estimates; interestingly, for unattractive music pieces, rating liking increased duration estimates, which may point to a "negative value heuristic," such that consumers estimate unattractive objects to be more abundant than they are.

The value heuristic may have functional origins as valuable things are typically scarce, prompting us to work harder to obtain them. However, our findings have possible implications of dysfunctional behavior in a number of areas. For example, the value heuristic may yield an intuitive misunderstanding of the basic economic relationship between value and supply, giving rise to market inefficiencies. If people heuristically use their subjective valuations as information to estimate supply, they may well underestimate the supply of what they value. Second, it is well established in economics and psychology that perceived scarcity enhances stimulus valuation. Coupled with these scarcity effects, a value heuristic may turn people into value pumps. If scarcity increases valuation, and if, in turn, value enhances perceived scarcity, then repeatedly alternating between valuation and frequency estimation might turn people into value pumps. Finally, the value heuristic may impact search behavior; consumers may stop searching for valuable alternatives too soon if they underestimate their true frequency of occurrence (e.g., during an online search of attractive hotels).

\section{"On Southbound Ease and Northbound Fees: Literal Consequences of the Metaphoric Link between Vertical Position and Cardinal Direction" \\ Leif Nelson, University of California, San Diego Joseph Simmons, Yale University}

Consumers' price expectations and shopping destinations are informed by judgments of distance and time. For example, to inform their purchasing decisions, people often try to identify which store is closer, which mode of transportation will be faster, and which freeway will have less traffic. Indeed, the minimization of distance and time plays a critical role in consumer decision making (Bell, Ho, and Tang 1998).

Different lines of research have emphasized how consumers fail to minimize travel, even when presented with an accurate map of the travel route. For example, when presented with a schematic map for airline travel, consumers show a preference for a route that continuously progresses towards the final goal, even if it takes longer than a comparable indirect route (Soman and Shi 2003). Furthermore, when shown a map featuring a number of stops on a possible shopping trip, consumers minimize the distance between stores even when it means traveling further from home and lengthening the total trip distance (Brooks, Kaufmann, and Lichtenstein 2004).

Particularly pertinent for the research presented here are findings suggesting that consumers may show consistent biases in their time and distance estimates even when presented with accurate maps of the trip. One set of findings, for example, showed that people underestimated distances in part because they were encoding travel times instead (Kang, Herr, and Page 2003). Another set of findings showed that underestimations of distance can be due to heuristic spatial processes that overemphasize direct distance (Raghubir and Krishna 1996). Indeed, a diverse set of studies show that consumers use a variety of psychological mechanisms to assess time and distance, and that these mechanisms often lead to counternormative assessments.

In this paper we extend these findings by identifying a thus far undocumented influence on consumers' spatial perceptions. Across all of the studies detailed above, researchers identified perceptual processes by using an objective source of spatial information (e.g., a map) to evaluate consumer estimates of, and preferences for, different times and distances. Nevertheless, a long line of research has emphasized that consumers are not merely imperfect processors of useful information; they are also prone to improperly using useless information (Bastardi and Shafir 1998; Carpenter, Glazer, and Nakamoto 1994; Meyvis and Janiszewski 2002). With that in mind, we suggest that the metaphors that people use to describe spatial relations can affect their judgments of distance and time.

Whether making reference to living "up north" or "down south," we often use the language of vertical position to describe cardinal direction. Such a metaphorical link may not be merely linguistic; rather, it may alter our mental representations of spatial relations, and consequently influence our beliefs and judgments. As a result, we hypothesize that consumers may rely on this metaphor to infer that destinations to the north are slightly uphill, and therefore harder to get to. Further, this inference may increase price expectations for northward services, and decrease the willingness to shop at northward destinations.

In Study 1, response latencies in an IAT paradigm demonstrated a strong implicit association between "north" and "up" and "south" and "down." In Study 2, people were more likely to infer 
that stimuli moving or facing downhill were oriented southward, despite the absence of any honest signals about cardinal direction. In Study 3, a secondary feature of downhill travel (i.e., ease of travel) showed similar effects. When people read about someone walking with ease, they were more likely to infer that she was walking south than when they read about someone walking with difficulty.

Next, we showed that these effects have consequence in consumer contexts. If people associate cardinal direction with slope, and slope with effort, then we expected to find corresponding effects in consumers' price expectations and choices. Consistent with this, people thought that it would be more expensive to ship to a northern city than to a southern city (Study 4) and they expected a moving company to charge more to move an apartment north than to move it south (Study 5). Study 6 investigated the implications of this metaphoric relationship for marketers' promotional efforts, finding that consumers expressed higher intentions to redeem a coupon that described an ice cream shop as south of a reference point than as north of a reference point. Finally, these effects were shown to depend on preferences for convenience. When people were choosing where to purchase an inexpensive item they were much more likely to choose a store to the south, presumably looking for the lowest effort option. When shopping for a much more expensive item, people were indifferent between the two options, reflecting a willingness to go to the higher effort northern location (Study 7). Taken together, these findings strongly suggest that the metaphor linking cardinal direction and vertical position can consequentially influence consumers' judgments, choices, and preferences.

\section{"Effects That Lead to Causes: Using an Event's Outcomes to Infer Its Causes" \\ Robyn LeBoeuf, University of Florida \\ Michael I. Norton, Harvard University}

Imagine an event, such as a computer crash. That event could have many possible causes, ranging from the minor (e.g., a malfunctioning cooling fan) to the extreme (e.g., deliberate sabotage by a hacker). The event could also have many possible outcomes, ranging from mere inconveniences (temporary loss of email) to large-scale disruptions (loss of important documents). We examine how an event's eventual outcomes influence perceptions of its most likely cause, even when the outcomes are completely uninformative about the event itself.

In Study 1, participants read that a small country's beloved president was assassinated by one of his countrymen; a British newspaper then criticized the late president, sparking global protests. Some then read that Britain responded aggressively to the protests, triggering war, whereas others read that Britain peacefully resolved the issue. Participants were then asked whether the initial assassination was more likely to have been perpetrated by one man or by a conspiracy internal to that country. As predicted, participants more often chose the conspiracy (large cause) when Britain triggered war (large outcome) than when peace prevailed, even though Britain was unconnected to the assassination. A follow-up study showed that perceptions of whether United States President John F. Kennedy's assassination involved a conspiracy could similarly be manipulated by describing "large" versus "small" effects of his death.

To investigate this effect's generality, in Study 2, participants read about a zoo in which the animals caught a disease. Some learned that the disease had a large outcome (almost all of the animals died) whereas others learned that the outcome was minor (few animals died). Participants also learned that the zoo had recently acquired a "small new rabbit" and a "new fully-grown bear" and were asked to choose which had most likely introduced the disease. The large cause (bear) was chosen more often when the disease's outcome was large than when it was small. Again, people think that large outcomes have (even literal, physical) large causes.

To examine this tendency in a consumer (product-failure) setting, in Study 3 participants read about a computer crash that destroyed a file containing a student's term paper. Participants either learned that the crash's outcome was severe (the professor did not grant an extension, so the student could not graduate) or mild (the professor granted an extension, and the student graduated as planned). Participants next indicated whether they thought the crash was more likely caused by an incorrectly installed cooling fan (small cause) or by an undetectable malicious virus (large cause). More selected the virus when the outcome was severe than when it was mild, even though the outcome was uninformative about the crash itself. Thus, the assignment of blame for a product failure may depend not just on the "local" circumstances of the failure itself, but also on the cascade of events that follow.

Having established widespread outcome-cause matching for size, we next explored whether people also match along another dimension: valence. Study 4's participants learned that a man was late for work because he did something thoughtless (started a fight with his wife) and then something thoughtful (stopped to buy his wife flowers). When the man was fired for being late, participants blamed his thoughtlessness for his lateness, but they blamed his thoughtfulness for the lateness when his day turned out quite positively, even though the absolute amount of "lateness" was the same in each case. This finding suggests that outcome-cause matching may be connected to "just world" beliefs (e.g., Lerner and Miller 1978), inasmuch as people may attempt to justify bad (good) outcomes by attending more to the bad (good) aspects of prior behavior. Indeed, Study 5 revealed that participants high in justworld beliefs are more likely to select a cause that matches an outcome's valence than are those low in such beliefs. Thus, there may be a motivational component to the current effects, with outcome-cause matching arising more often among those who are motivated to see the world as a "just" and predictable place.

Study 6 further examined the underpinnings of the current effects. Some participants saw a film clip illustrating the butterfly effect (the idea that small changes can have large future consequences) but others saw a neutral, control clip. Participants then read the severe-outcome version of Study 3's computer crash. Those exposed to the butterfly effect were less likely to select a large cause for the severe outcome than those not so exposed, suggesting that outcome-cause matching (which may naturally be an accessible principle) can be supplanted if another causal schema is evoked instead. Interestingly, priming the butterfly effect had a larger impact among those high (versus low) in need for closure, suggesting that those who are most motivated to see the world as predictable are also the most likely to use the salient causal schema to explain the world, whether that schema involves matching or some other pattern (see Kruglanski 1987).

We thus suggest a regularity in causal reasoning: people rely upon an event's eventual outcomes to help them infer the event's prior causes, especially if they are motivated to make sense of the world and unless another causal schema is primed. This pattern is often reasonable (many large effects indeed have large causes), but such outcome-cause matching (reminiscent of the representativeness heuristic and referred to as the "resemblance criterion" by Nisbett \& Ross, 1980, but never tested empirically) can lead people astray when outcomes are uninformative about potential causes. The current results have implications for theories of causal reasoning, and the implications for consumer behavior seem clear: for example, when a given product failure (e.coli contamination) has 
a large outcome (many people die), consumers may be more likely to search for a large cause (corporate malfeasance) than when the failure is the same but the outcome is, for arbitrary reasons, smaller (many are sickened, but timely medical treatment prevents fatalities).

\section{REFERENCES}

Adaval, Rashmi. (2001). Sometimes It Just Feels Right: The Differential Weighting of Affect-Consistent and AffectInconsistent Product Information. Journal of Consumer Research, 28(1), 1.

Ariely, Dan, George Loewenstein and Drazen Prelec (2003). 'Coherent arbitrariness': Stable demand curves without stable preferences. Quarterly Journal of Economics, 118(1), 73.

Ariely, Dan, George Loewenstein and Drazen Prelec (2006). Tom Sawyer and the construction of value. Journal of Economic Behavior \& Organization, 60(1), 1-10.

Bastardi, Anthony and Eldar Shafir (1998), "On the pursuit and misuse of useless information," Journal of Personality and Social Psychology, 75 (July), 19-32.

Bell, David R, Teck-Hua Ho and Christopher S. Tang (1998), "Determining Where to Shop: Fixed and Variable Costs of Shopping," Journal of Marketing Research, 35 (August), 352-369.

Bickart, Barbara and Norbert Schwarz (2001). Service Experiences and Satisfaction Judgments: The Use of Affect and Beliefs in Judgment Formation. Journal of Consumer Psychology, 11(1), 29-41.

Brooks, Charles M, Patrick J. Kaufmann and Donald R. Lichtenstein (2004), "Travel Configuration on Consumer Trip-Chained Store Choice," Journal of Consumer Research, 31 (September), 241-248.

Carpenter, Gregory S, Rashi Glazer and Kent Nakamoto (1994), "Meaningful brands from meaningless differentiation: The dependence on irrelevant attributes," Journal of Marketing Research, 31 (August), 339-350.

Cialdini, Robert. B. (2001). Influence: Science and practice. Glenview, IL: Scott Foresman.

Cohen, Joel B. and Americus Reed II (2006). A Multiple Pathway Anchoring and Adjustment (MPAA) Model of Attitude Generation and Recruitment. Journal of Consumer Research, 33(1), 1-15.

Folkes, Valerie S. (1988). The Availability Heuristic and Perceived Risk. Journal of Consumer Research, 15(1), 13.

Gilovich, Thomas, Dale Griffin and Daniel Kahneman (2002). Heuristics and biases: The psychology of intuitive judgment. Cambridge University Press.

Kahneman, Daniel, Paul Slovic and Amos Tversky (1982). Judgment under uncertainty: Heuristics and biases. Cambridge University Press.

Kruglanski, Arie W. (1987), "Blame-placing schemata and attributional research," in Changing conceptions of conspiracy, ed. Carl F. Graumann and Serge Moscovici, New York: Springer Verlag, 219-29.

Labroo, Aparna. A. and Angla Y. Lee (2006). Between Two Brands: A Goal Fluency Account of Brand Evaluation. Journal of Marketing Research, 43(3), 374-385.

Lerner, Melvin J. and Dale T. Miller (1978), "Just World Research and the Attribution Process: Looking Back and Looking Ahead," Psychological Bulletin, 85 (5), 1030-51.

Lynch Jr, John G. (2006). Accessibility-Diagnosticity and the Multiple Pathway Anchoring and Adjustment Model. Journal of Consumer Research, 33(1), 25-27.
Menon, Geeta and Priya Raghubir (2003). Ease-of-Retrieval as an Automatic Input in Judgments: A Mere-Accessibility Framework? Journal of Consumer Research, 30(2), 230-243.

Meyvis, Tom and Chris Janiszewski (2002), “Consumers' beliefs about product benefits: The effect of obviously irrelevant product information," Journal of Consumer Research, 28 (March), 618-635.

Nisbett, Richard E. and Lee Ross (1980), Human Inference: Strategies and Shortcomings of Intuitive Judgment. Englewood Cliffs: Prentice-Hall.

Pham, Michel T. (1998). Representatives, relevance, and the use of feelings in decision making. Journal of Consumer Research, 25(2), 144.

Raghubir, Priya and Aradhna Krishna (1996), "As the Crow Flies: Bias in Consumers' Map-based Distance Judgments, Journal of Consumer Research. Vol 23 (June), 26-39.

Simonson, Itamar and Aimee Drolet (2004). Anchoring Effects on Consumers' Willingness-to- Pay and Willingness-toAccept. Journal of Consumer Research, 31(3), 681-690.

Soman, Dilip and Mengze Shi (2003), "Virtual Progress: The Effect of Path Characteristics on Perceptions of Progress and Choice," Management Science, 49 (September), 1229-1250.

Tversky, Amos and Daniel Kahneman (1974). Judgment under uncertainty: Heuristics and biases. Science, 185(4157), 1124.

Tybout, Alice M., Brian Sternthal, Prashant Malaviya, Georgios A. Bakamitsos and Se-Bum Park (2005). Information Accessibility as a Moderator of Judgments: The Role of Content versus Retrieval Ease. Journal of Consumer Research, 32(1), 76-85.

Wansink, Brian, Robert J. Kent and Stephen J. Hoch (1998). An anchoring and adjustment model of purchase quantity decisions. Journal of Marketing Research, 35(1), 71-81. 